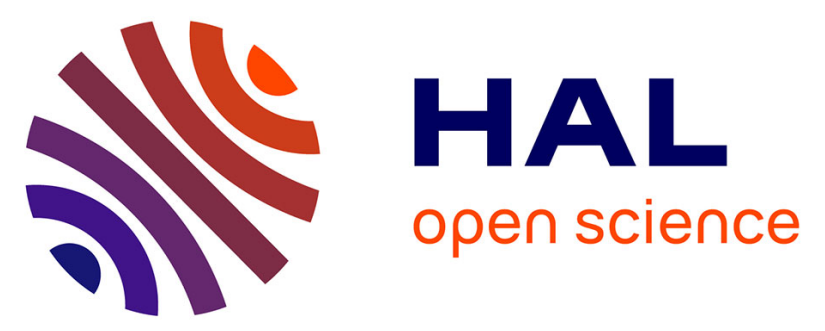

\title{
Stage-specific expression of the proline-alanine transporter in the human pathogen Leishmania
}

T. Liburkin-Dan, D. Schlisselberg, R. Fischer-Weinberger, Pascale Pescher, E. Inbar, M. Ephros, D. Rentsch, Gerald F Späth, D. Zilberstein

\section{- To cite this version:}

T. Liburkin-Dan, D. Schlisselberg, R. Fischer-Weinberger, Pascale Pescher, E. Inbar, et al.. Stagespecific expression of the proline-alanine transporter in the human pathogen Leishmania. Molecular and Biochemical Parasitology, 2018, 222, pp.1-5. 10.1016/j.molbiopara.2018.04.002 . pasteur01974297

\section{HAL Id: pasteur-01974297}

\section{https://hal-pasteur.archives-ouvertes.fr/pasteur-01974297}

Submitted on 14 Feb 2019

HAL is a multi-disciplinary open access archive for the deposit and dissemination of scientific research documents, whether they are published or not. The documents may come from teaching and research institutions in France or abroad, or from public or private research centers.
L'archive ouverte pluridisciplinaire HAL, est destinée au dépôt et à la diffusion de documents scientifiques de niveau recherche, publiés ou non, émanant des établissements d'enseignement et de recherche français ou étrangers, des laboratoires publics ou privés.

\section{(1)(1) $\$(0)$}

Distributed under a Creative Commons Attribution - NonCommercial - ShareAlikel 4.0 


\section{Stage-specific expression of the proline-alanine transporter in the}

\section{human pathogen Leishmania}

Liburkin-Dan, T. ${ }^{1}$, Schlisselberg, D. ${ }^{1}$, Fischer-Weinberger, R. ${ }^{1}$, Pescher, P. ${ }^{2}$, Inbar, E. ${ }^{1 \uparrow}$, Ephros M., Rentsch, D. ${ }^{3}$, Späth, G.F. ${ }^{2}$, and Zilberstein, D. ${ }^{1 *}$

${ }^{1}$ Faculty of Biology, Technion - Israel Institute of Technology, Haifa 3200003, Haifa, Israel

${ }^{2}$ Institut Pasteur, INSERM U1201, Unité de Parasitologie moléculaire et Signalisation, 75015

Paris, France

${ }^{3}$ Institute of Plant Sciences, University of Bern, Altenbergrain 21, 3013 Bern, Switzerland

Corresponding author: Dan Zilberstein

Faculty of Biology

Technion-Israel Institute of Technology

Haifa 3200003, Israel

email: danz@technion.ac.il

tel: 9724778873647

TCurrent address: $\quad$ Laboratory of Parasitic Diseases

National Institute of Allergy and Infectious Diseases

National Institutes of Health

Bethesda, MD 20892, USA 


\begin{abstract}
Leishmania are obligatory intracellular parasites that cycle between the sand fly midgut (extracellular promastigotes) and mammalian macrophage phagolysosomes (intracellular amastigotes). They have developed mechanisms of adaptation to the distinct environments of host and vector that favor utilization of both proline and alanine. LdAAP24 is the L. donovani proline-alanine transporter. It is a member of Leishmania system A that translocates neutral amino acids. Since system A is promastigote-specific, we aimed to assess whether LdAAP24 is also expressed exclusively in promastigotes. Herein, we established that upon exposing $L$. donovani promastigotes to amastigote differentiation signal ( $\mathrm{pH} 5.5$ and $\left.37^{\circ} \mathrm{C}\right)$, parasites rapidly and completely degrade LdAAP24 protein in both axenic and in spleen-derived amastigotes. In contrast, LdAAP24 mRNA remained unchanged throughout differentiation. Addition of either MG132 or Bafilomycin A1 partially inhibited LdAAP24 protein degradation, indicating a role for both lysosome- and proteasome-mediated degradation. This work provides the first evidence for post-translational regulation of stage-specific expression of LdAAP24.
\end{abstract}




\section{Introduction}

Protozoan parasites of the genus Leishmania cause morbidity and mortality throughout large areas of the Old and New World and are the causative agents of a wide spectrum of human and veterinary diseases. The clinical manifestations of Leishmania infections range from lesions of the skin and mucous membranes to lethality, the latter caused by visceral species [1].

Leishmania exhibit a digenetic life cycle that includes extracellular promastigote and intracellular amastigote forms. Extracellular promastigotes develop in the alimentary tract of sand flies. Following transmission to humans, promastigotes differentiate into obligatory intracellular amastigotes within macrophage phagolysosomes [2, 3]. This differentiation process in the host can be mimicked in axenic culture by shifting promastigotes from an insect-like $\left(26^{\circ} \mathrm{C}\right.$, pH 7) to an intra-lysosomal-like environment $\left(37^{\circ} \mathrm{C}, \mathrm{pH} 5.5\right.$ and $\left.5 \% \mathrm{CO}_{2}\right)$ [4-6]. Axenic differentiation of L. donovani has been extensively characterized over the last two decades, establishing that this is a genetically programmed process [7-10].

During their life cycle, Leishmania move between relatively alkaline environments rich in sugar and amino acids (AAs) and acidic environments rich in fatty acids and AAs [3, 11-13]. High AA abundance is a feature common to both environments and accordingly, the parasites display adaptive mechanisms that favor utilization of such compounds $[12,14,15]$. In particular, Leishmania exhibit large intracellular AA pool, of which alanine and proline are the main components [15-17]. The parasites use these AAs as osmolytes and as alternative sources of carbon.

In 1999, we biochemically showed that L. donovani take up proline via three systems named A, B and C [18]. Systems A and B are active only in promastigotes whereas system C is amastigotes-specific. Similarly, proline transport in T. cruzi was considered to be mediated by 
multiple transporters, each possessing distinct biochemical properties [19]. More recently, we established that the low affinity, high capacity proline transporter in L. donovani (system A) is encoded by two identical copies of LdAAP24 (LinJ.10.0760 and LinJ.10.0770)[16]. Notably, we discovered that due to distinct trans-splicing sites, the two gene copies produce mRNAs and corresponding proteins that differ in size and function [20]. The protein encoded by LinJ.10.0770 (named LdAAP24.2) transports both alanine and proline, whereas the one encoded by LinJ.10.0760 (named LdAAP24.1) is 18 amino acids shorter and transports only proline. LdAAP24 plays a critical role in maintaining intracellular AA homeostasis and in responses to hypotonic stress [20].

To date, our analyses of LdAAP24 activity and expression were carried out in promastigotes. Previous biochemical studies suggested that amastigotes import proline via transport systems distinct from that of promastigotes [18]. This prompted us to examine LdAAP24 expression in both intracellular and axenic amastigotes. We found that once promastigotes were exposed to conditions that initiate differentiation into amastigotes, rapid degradation of LdAAP24 protein was induced. In macrophages, down-regulation of both variants (e.g. LdAAP24.1 and LdAAP24.2) was slower than in axenic conditions. In contrast, hamsterderived amastigotes do not express LdAAP24 protein at all. Changes in protein expression did not parallel mRNA abundance indicating posttranslational regulation of stage-specific expression of LdAAP24. 


\section{Materials and Methods}

\section{Materials}

Ampicillin, G418, Hygromycin B, Phleomycin, Blasticidin, medium-199 (M-199), MG-132 and Bafilomycin A1 were from Sigma. Fetal bovine serum (FBS) was from Biological Industries Ltd.. n-dodecyl $\beta$-D-maltoside (DDM) was from Calbiochem and magnetic beads-bound anti-HA were from Medical\&Biological Laboratories Co., Ltd. (MBL). All other reagents were of analytical grade.

\section{Axenic Leishmania cell culture}

L. donovani, MHOM/SD/00/1S cell line was used [21]. Promastigotes and amastigotes were grown and maintained in axenic cultures. Differentiation was performed as previously described [5]. Briefly, late log promastigotes were transferred from promastigote medium at $26^{\circ} \mathrm{C}$ and $\mathrm{pH} 7.4$ to amastigote medium at $37^{\circ} \mathrm{C}$, pH 5.5 in $5 \% \mathrm{CO}_{2}$ environment.

\section{Western blot analysis and dot blot analysis}

Western blot analyses of proteins were carried out as previously described [17]. Briefly, each lane was loaded with $10 \mu \mathrm{g}$ of cellular protein. Following transfer to Protean BA-83 nitrocellulose paper (Whatman 1td.), parasite proteins were exposed to Rabbit anti LdAAP24 (1:2000 serum dilution) or anti HSP83 (1:2000) antisera [16, 21]. LdAAP24 band density relative to that of HSP83 was calculated using TINA2.0 software.

In vitro macrophage infection with L. donovani 
THP1 macrophage maintenance and infection were carried out as previously described [22]. Briefly, macrophages were grown on a plate at $37^{\circ} \mathrm{C}$ in a $5 \% \mathrm{CO}_{2}$ incubator at a density of $10^{7}$ cells/plate. Late log-phase $L$. donovani promastigotes were added to the culture for 4 hours at 1:10 macrophage to parasite ratio. Plates were then washed three times with phosphate buffered saline (PBS) and incubation continued for 48 hours. To confirm infection, round cover-slips $(18 \mathrm{~mm})$ were added to the dishes before addition of macrophages, stained with Giemsa after the experimental procedure, and viewed in an electron microscope.

\section{Purification of macrophage- and splenic-derived amastigotes}

THP1 macrophages were grown on 8 plates at $37^{\circ} \mathrm{C}$ at a density of $1 \times 10^{7}$ cells/plate and then infected with mid-log phase $L$. donovani promastigotes as above. 48 hours after infection, macrophages were collected using a scraper and washed with ice-cold PBS for 4 minutes at 48Xg. Pellets were finally suspended in $1 \mathrm{ml} \mathrm{PBS}$ and transferred to microcentrifuge tubes. Separation of amastigotes was facilitated initially by passing the pellet repeatedly through a $1 \mathrm{ml}$ syringe with a $27 \mathrm{G}$ needle. Lysates were then centrifuged for 15 minutes at $2500 \mathrm{Xg}$ at $4^{\circ} \mathrm{C}$. The pellet was then suspended in $45 \%$ Percoll, which built the middle layer of the Percoll gradient as described in [22]. Cells were then isolated from the interface between the layers and subsequently centrifuged at $3500 \mathrm{Xg}$ for 60 minutes at $4^{\circ} \mathrm{C}$ as previously described [23]. Spleenderived amastigotes were isolated from 100 days L. donovani-infected hamsters as described previously [24].

Confocal immunofluorescence microscopy 
Immunofluorescence of LdAAP24 in axenic $L$. donovani promastigotes and amastigotes was carried out as in [16] using Zeiss LSM 510 META and Zeiss LSM 700 microscopes. For immunofluorescence of parasite-infected macrophages, cover slips were stained with antiLdAAP24 and DAPI employing the protocol used for promastigotes [16].

\section{Northern Blot}

Total RNA from L. donovani promastigotes (either starved for arginine or non-starved) was prepared and subjected to Northern blotting of $L d A A P 3$ as described before [21]. Probes were amplified using the following primers: LinJ.31.900 AAP3 Forward: 5'-

ATCATGAATTCATGAGCAAGCCCAGCAAGT-3'. Reverse: 5'GCTTAGTCGACCGGAAGATGATGTTGCGC-3’ 


\section{Results}

Differentiation signal induces rapid degradation of LdAAP24

Exposing axenic $L$. donovani promastigotes to amastigote differentiation signal induced rapid disappearance of the two LdAAP24 variants (Fig. 1A). As indicated by western blot analysis, within three hours only traces of the transporter proteins remained. Time course analysis determined the rate of degradation at $\mathrm{t}_{1 / 2}=35 \pm 3.3$ minutes (Fig. 1B). Moreover, both short ( 8 weeks) and long (25 weeks) passages of axenic promastigotes [24], representing virulent and highly attenuated parasites, down-regulated LdAAP24 equally (Fig. 1C). These observations are consistent with our previous report that proline transport rate in axenic amastigotes is 5 times slower than in promastigotes, likely mediated by a different transport system $[16,18]$.

Further analysis of whether protein abundance down-regulation depends on the differentiation signal indicates that neither exposure to $\mathrm{pH} 5.5$ nor to $37^{\circ} \mathrm{C}$ alone initiated degradation (Fig. 2). Only subjecting promastigotes to the full differentiation signal initiated complete LdAAP24 protein degradation in axenic culture. Note that exposing L. donovani promastigotes to $\mathrm{pH} 5.5$ alone caused minor degradation of the heavier variant of LdAAP24 (LdAAP24.2). However, degradation was complete only in cells exposed to both $37^{\square} \mathrm{C}$ and $\mathrm{pH}$ 5.5 .

The rapid and complete degradation of LdAAP24 at the onset of $L$. donovani axenic differentiation prompted us to assess whether the same happens in vivo, during macrophage infection. Human THP1 monocytes were incubated with L. donovani promastigotes for four hours and then incubated for additional 48 hours [22]. Intracellular amastigotes were then purified from the infected macrophages and assayed for LdAAP24 protein abundance. As shown 
by western blot analysis (Fig. 3A), while axenic amastigotes lacked visible level of LdAAP24, macrophage-derived amastigotes expressed LdAAP24 protein, though, at lower level compared to promastigotes. This indicated that exposing parasites to phagolysosome environment induced LdAAP24 down-regulation, but not to complete disappearance as in axenic parasites.

Indirect immunofluorescence analysis validated the western blot data that whereas axenic amastigotes do not express LdAAP24 at all (Fig. 3B and C), amastigotes obtained from infected THP1 cells at 48h post-infection did express visible level of this protein (Fig. 3D). To further assess whether LdAAP24 is expressed in long-term intracellular amastigotes, they have been isolated from spleens of 100 days infected hamsters. Western blot analysis clearly demonstrated (Fig. 1C) that long-term hamster-derived L. donovani do not express LdAAP24 protein. The analysis of axenic and intracellular $L$. donovani indicate that in the latter LdAAP24 degrade much slower than in the host-free culture, likely due to intracellular element(s) that slow transporter degradation.

\section{Degradation of LdAAP24 is lysosome-mediated and dependent on proteasome activity}

Vince et al. [25] previously provided evidence for posttranslational regulation of stagespecific expression of the glucose and inositol transporters in L. mexicana. Exposure to differentiation conditions, in both axenic culture and macrophages, induced lysosome-mediated degradation. Using axenic amastigotes they showed that mono-ubiquitination triggered degradation and targeting to lysosomes. As shown in Fig. 4, addition of $10 \mu \mathrm{M}$ of the proteasome inhibitor MG132 to axenic $L$. donovani differentiation medium at time zero partially (57\%) inhibited LdAAP24 degradation. Bafilomycin A1 is a specific inhibitor of lysosome vacuolar 
ATPase that blocks acidification of this organelle [26]. Adding $1 \mu \mathrm{M}$ Bafilomycin A1 to amastigote differentiation medium also partially (76\%) inhibited degradation of LdAAP24.

To assess whether the changes in LdAAP24 protein expression correlate with similar change in mRNA abundance, we performed northern-blot of LdAAP24 open reading frame. No significant change in mRNA was observed after exposing promastigotes to differentiation signal (Fig. 5). 


\section{Discussion}

This study aimed to molecularly validate the previous biochemically-based observation that L. donovani transport system A is active only in promastigotes [18]. In amastigotes another low affinity and specificity system (system C) translocates several amino acids including proline [18]. Analysis of protein and mRNA abundance in axenic amastigotes, promastigotes and intracellular amastigotes confirmed that system A, represented by LdAAP24 is expressed and active only in promastigotes. Exposing L. donovani promastigote to amastigote differentiation signal initiated rapid degradation of LdAAP24 protein. In axenic promastigotes degradation was rapid $\left(\mathrm{T}_{1 / 2}=35\right.$ minutes $)$, while in intracellular amastigotes degradation was slower, LdAAP24 protein was visible 48 hours after macrophage infection, but not in splenic amastigotes recovered after100 days of infection.

LdAAP24 stage-specific expression is regulated at the level of protein abundance (posttranslational) only. We showed that degradation was susceptible to treatment with both the proteasome inhibitor MG132 and the V-ATPase inhibitor Bafilomycin A1, suggesting that LdAAP24 degradation is mediated by both the lysosome and proteasome.

Usually, membrane protein degradation is mediated via the lysosome pathway. Vince et al. [25] showed that upon L. mexicana differentiation into amastigotes the promastigote-specific myo-inositol transporter D1 actively degrades via the lysosomes-mediated pathway. Similarly, the dolichol-phosphate-mannose synthase [27], the multidrug resistance protein 1 [28] and the folate transporter 1 [29] are all stage-specific whose abundance is down-regulated by the lysosome mediated pathway. Likewise, in the present study, inhibition by Bafilomycin A1 indicates a role for the lysosome in LdAAP24 degradation. 
This work provides the first evidence for post- translational regulation of stage-specific expression of LdAAP24. It also provides an additional evidence that axenic Leishmania resemble intracellular parasites. 


\section{Acknowledgements}

We thank Dr. Harsh Pawar and Yael Bar Avraham for technical help. We also thanks Dr. Avital

Bareket Samish for editing this manuscript. This study was supported by grant number 1766/16 and from the Israel Science Foundation. 


\section{Figure Legends}

Figure 1. Rapid down-regulation of LdAAP24 abundance during first phase of $L$. donovani axenic differentiation.

[A] Western blot analysis of LdAAP24 degradation during axenic differentiation in wild type (WT) promastigotes. Time indicates hours after exposing promastigotes to differentiation to amastigotes signal. [B] Time course of LdAAP24 down-regulation during axenic differentiation. Analysis was carried out using western blot analysis at indicated hours after exposing promastigotes to differentiation signal. This figure is representative of five independent repeats. [C]. Western blot analysis of LdAAP24 in splenic amastigotes and axenic L. donovani promastigotes derived from the splenic amastigotes and maintained for $8(8 \mathrm{~W})$ and 25 weeks $(25 \mathrm{~W})$ in culture. Proteins were extracted from 100 days old splenic amastigotes or axenic promastigotes (at 0 and 3 hours after differentiation signal). In all panels LdHSP83 was used as loading control

Figure 2. Promastigote to amastigote differentiation signal, not acidic pH or elevated temperature alone, initiate LdAAP24 degradation.

Western blot analysis of LdAAP24 degradation during exposure of the parasites to either pH 5.5, $37^{0} \mathrm{C}$ or both ('complete differentiation signal'). Time indicates hours after exposure to indicated signal components. Parasite actin was used as loading control.

Figure 3. LdAAP24 undergoes partial degradation during first 48 hours of macrophage infection.

[A] Western blot analysis of LdAAP24 degradation in promastigotes, mature axenic amastigotes and intracellular parasites $48 \mathrm{~h}$ after THP1 macrophage infection with promastigotes. Anti 
LdHSP83 was used as loading control. [B-D] Confocal immunofluorescence microscopy (Zeiss LSM 700) of LdAAP24 expression in axenic promastigotes, axenic amastigotes and infected THP-1 macrophages, respectively, was determined by anti- LdAAP24 primary antibody, with

fluorescent CY3 anti rabbit as secondary antibody (red). DAPI was used to stain the nucleus and kinetoplast (blue).

Figure 4. LdAAP24 degradation is lysosome and proteasome- dependent.

Axenic promastigotes were subjected to 3-hours differentiation with (+) or without (-) MG-132 and/or Bafilomycin A1 (Baf A1). Anti-LdAAP24 was used to determine LdAAP24 expressionlevels and LdHSP83 was used as loading control (upper panel). Densitometry of each band relative to HSP83 is illustrated in the lower panel.

Figure 5. mRNA levels of LdAAP24 do not change during axenic differentiation.

Total RNA was extracted from $L$. donovani promastigotes and at $0.5,1$ and 3 hours after exposure to promastigote to amastigote differentiation signal and subjected to northern analysis as described in Materials and Methods. LdAAP24 open reading frame was used as a probe. rRNA was used as loading control. This experiments is representative of three independent repeats. 


\section{References}

1. Herwaldt BL. Leishmaniasis. Lancet. 1999;354(9185):1191-9. Epub 1999/10/08. doi: S0140-6736(98)10178-2 [pii] 10.1016/S0140-6736(98)10178-2. PubMed PMID: 10513726.

2. Chang KP, Dwyer DM. Multiplication of a human parasite (Leishmania donovani) in phagolysosomes of hamster macrophages in vivo Science. 1976;193:678-80. PubMed PMID: 381.

3. McConville MJ, de Souza D, Saunders E, Likic VA, Naderer T. Living in a phagolysosome; metabolism of Leishmania amastigotes. Trends Parasitol. 2007;23(8):368-75. PubMed PMID: 17606406.

4. Debrabant A, Joshi MB, Pimenta PF, dwyer DM. Generation of Leishmania donovani axenic amastigotes: their growth and biological characteristics. IntJParasitol. 2004;34(2):205-17. PubMed PMID: 6876.

5. Barak E, Amin-Spector S, Gerliak E, Goyard S, Holland N, Zilberstein D. Differentiation of Leishmania donovani in host-free system: analysis of signal perception and response. Mol Biochem Parasitol. 2005;141(1):99-108. PubMed PMID: 15811531; PubMed Central PMCID: PMC15811531

6. Bates PA, Robertson CD, Tetley L, Coombs GH. Axenic cultivation and characterization of Leishmania mexicana amastigote-like forms. Parasitology. 1992;105 ( Pt 2):193-202. Epub 1992/10/01. PubMed PMID: 1454417.

7. Rosenzweig D, Smith D, Opperdoes FR, Stern S, Olafson RW, Zilberstein D. Retooling Leishmania metabolism: from sandfly gut to human macrophage. FASEB Journal. 2008;22(2):590-602. PubMed PMID: 8904. 
8. Lahav T, Sivam D, Volpin H, Ronen M, Tsigankov P, Green A, et al. Multiple levels of gene regulation mediate differentiation of the intracellular pathogen Leishmania. FASEB J. 2011;25(2):515-25. Epub 2010/10/19. doi: fj.10-157529 [pii] 10.1096/fj.10-157529. PubMed PMID: 20952481.

9. Tsigankov P, Gherardini PF, Helmer-Citterich M, Spaeth GF, Myler PJ, Zilberstein D. Regulation dynamics of Leishmania differentiation: deconvoluting signals and identifying phosphorylation trends. Mol Cell Proteomics. 2014;13:1769-86. doi: 10.1074/mcp.M114.037705. PubMed PMID: 24741111.

10. Zilberstein D. Proteomic analysis of posttranslational modifications using iTRAQ in Leishmania. Methods Mol Biol. 2015;1201:261-8. doi: 10.1007/978-1-4939-1438-8_16. PubMed PMID: 25388120.

11. Burchmore RJ, Barrett MP. Life in vacuol. IntJParasitol. 2001;31(12):1311-20. PubMed PMID: 4066.

12. Opperdoes FR, Coombs GH. Metabolism of Leishmania: proven and predicted. Trends Parasitol. 2007;23:149-58. PubMed PMID: 8576.

13. Bringaud F, Barrett MP, Zilberstein D. Multiple roles of proline transport and metabolism in trypanosomatids. Front Biosci. 2012;17:349-74. Epub 2011/12/29. PubMed PMID: 22201748.

14. Rosenzweig D, Smith D, Opperdoes F, Stern S, Olafson RW, Zilberstein D. Retooling Leishmania metabolism: from sand fly gut to human macrophage. FASEB J. 2008;22(2):590-602. doi: 10.1096/fj.07-9254com. PubMed PMID: 17884972. 
15. Simon MW, Jayasimhulu K, Mukkada AJ. The free amino acid pool in Leishmania tropica promastigotes. Molecular and Biochemical Parasitology. 1983;9(1):47-57. PubMed PMID: 7386.

16. Inbar E, Schlisselberg D, Suter Grotemeyer M, Rentsch D, Zilberstein D. A versatile proline-alanine transporter in the unicellular pathogen Leishmania donovani regulates amino acid homeostasis and osmotic stress responses. Biochem J. 2013;449:555-66. Epub 2012/09/22. doi: 10.1042/BJ20121262. PubMed PMID: 22994895.

17. Darlyuk I, Goldman A, Roberts SC, Ullman B, Rentsch D, Zilberstein D. Arginine homeostasis and transport in the human pathogen Leishmania donovani. J Biol Chem. 2009;284:19800-7. Epub 2009/05/15. doi: M901066200 [pii] 10.1074/jbc.M901066200. PubMed PMID: 19439418.

18. Mazareb S, Fu ZY, Zilberstein D. Developmental regulation of proline transport in Leishmania donovani. Exp Parasitol. 1999;91(4):341-8. PubMed PMID: 4861.

19. Silber AM, Tonelli RR, Martinelli M, Colli W, Alves MJ. Active transport of L-proline in Trypanosoma cruzi. J Eukaryot Microbiol. 2002;49(6):441-6. Epub 2002/12/31. PubMed PMID: 12503677.

20. Schlisselberg D, Mazarib E, Inbar E, Rentsch D, Myler PJ, Zilberstein D. Size does matter: 18 amino acids at the N-terminal tip of an amino acid transporter in Leishmania determine substrate specificity. Sci Rep. 2015;5:16289-98. doi: 10.1038/srep16289. PubMed PMID: 26549185; PubMed Central PMCID: PMCPMC4637868.

21. Saar Y, Ransford A, Waldman E, Mazareb S, Amin-Spector S, Plumblee J, et al. Characterization of developmentally-regulated activities in axenic amastigotes of 
Leishmania donovani. Mol Biochem Parasitol. 1998;95(1):9-20. PubMed PMID: 9763285.

22. Goldman-Pinkovich A, Balno C, Strasser R, Zeituni-Molad M, Bendelak K, Rentsch D, et al. An Arginine Deprivation Response Pathway Is Induced in Leishmania during Macrophage Invasion. PLoS Pathog. 2016;12(4):e1005494. doi:

10.1371/journal.ppat.1005494. PubMed PMID: 27043018.

23. Chang KP. Human cutaneous lieshmaniasis in a mouse macrophage line: propagation and isolation of intracellular parasites. Science. 1980;209(4462):1240-42. PubMed PMID: 7403880.

24. Pescher P, Blisnick T, Bastin P, Spath GF. Quantitative proteome profiling informs on phenotypic traits that adapt Leishmania donovani for axenic and intracellular proliferation. Cell Microbiol. 2011;13(7):978-91. Epub 2011/04/20. doi: 10.1111/j.14625822.2011.01593.x. PubMed PMID: 21501362.

25. Vince JE, Tull D, Landfear S, McConville MJ. Lysosomal degradation of Leishmania hexose and inositol transporters is regulated in a stage-, nutrient- and ubiquitin-dependent manner. Int J Parasitol. 2011;41(7):791-800. Epub 2011/03/31. doi:

10.1016/j.ijpara.2011.02.003. PubMed PMID: 21447343.

26. Tapper H, Sundler R. Bafilomycin A1 inhibits lysosomal, phagosomal, and plasma membrane $\mathrm{H}(+)$-ATPase and induces lysosomal enzyme secretion in macrophages. J Cell Physiol. 1995;163(1):137-44. doi: 10.1002/jcp.1041630116. PubMed PMID: 7896890.

27. Mullin KA, Foth BJ, Ilgoutz SC, Callaghan JM, Zawadzki JL, McFadden GI, et al. Regulated degradation of an endoplasmic reticulum membrane protein in a tubular 
lysosome in Leishmania mexicana. Mol Biol Cell. 2001;12(8):2364-77. PubMed PMID: 11514622; PubMed Central PMCID: PMCPMC58600.

28. Dodge MA, Waller RF, Chow LM, Zaman MM, Cotton LM, McConville MJ, et al. Localization and activity of multidrug resistance protein 1 in the secretory pathway of Leishmania parasites. molecular microbiology. 2004;51(6):1563-75. PubMed PMID: 6792.

29. Richard D, Leprohon P, Drummelsmith J, Ouellette M. Growth phase regulation of the main folate transporter of leishmania infantum and its role in methotrexate resistance. Journal of Biological Chemistry. 2004. PubMed PMID: 7205.

30. Shaked-Mishan P, Suter-Grotemeyer M, Yoel-Almagor T, Holland N, Zilberstein D, Rentsch D. A novel high-affinity arginine transporter from the human parasitic protozoan Leishmania donovani. Mol Microbiol. 2006;60(1):30-8. PubMed PMID: 16556218.

31. Castilho-Martins EA, Laranjeira da Silva MF, dos Santos MG, Muxel SM, FloeterWinter LM. Axenic Leishmania amazonensis promastigotes sense both the external and internal arginine pool distinctly regulating the two transporter-coding genes. PLoS One. 2011;6(11):e27818. doi: 10.1371/journal.pone.0027818. PubMed PMID: 22114701; PubMed Central PMCID: PMC3218042. 
Figure 1
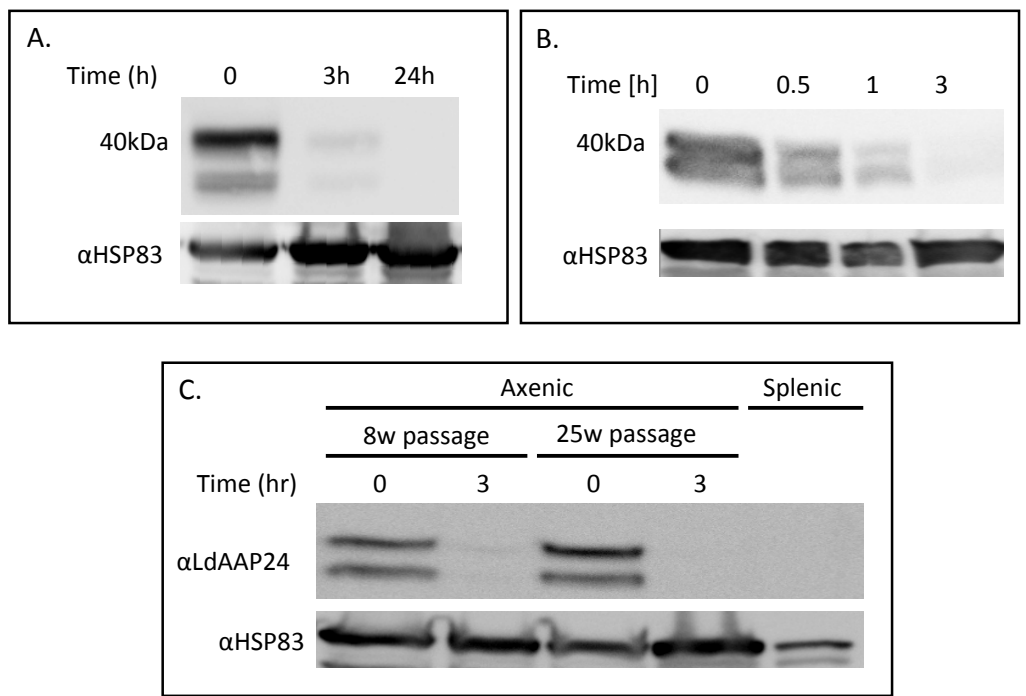

Fig. 1. Rapid down-regulation of LdAAP24 abundance during first phase of $L$. donovani axenic differentiation. 
Figure 2

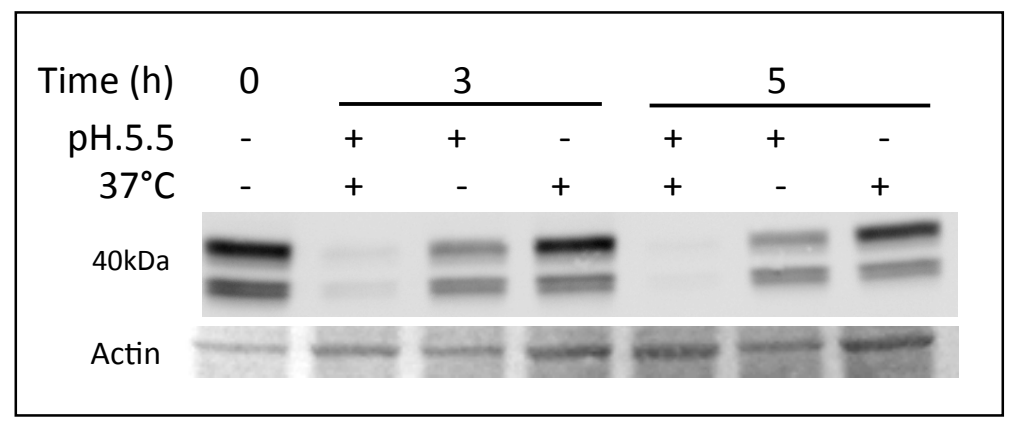

Fig. 2. Promastigote to amastigote differentiation signal, not acidic pH or elevated temperature alone, initiate LdAAP24 degradation. 
Figure 3

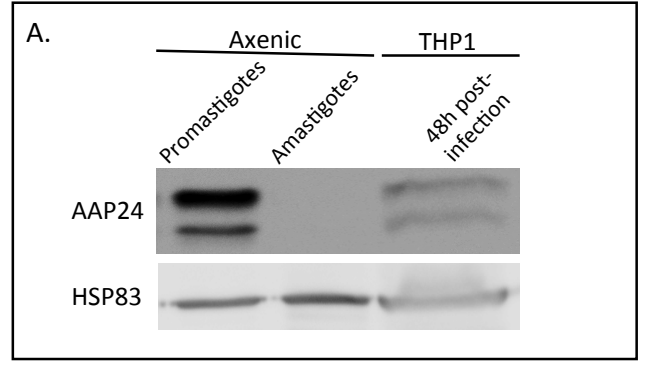

B.

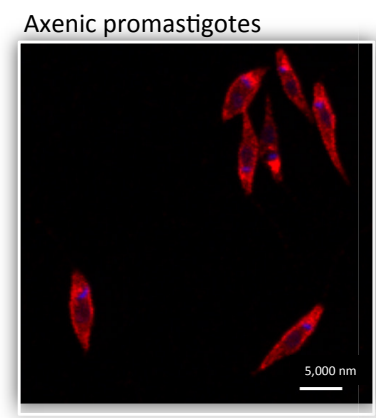

C.

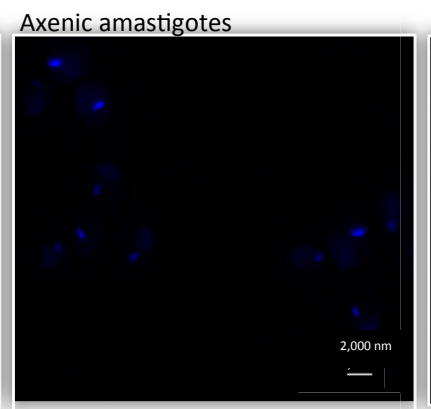

D.

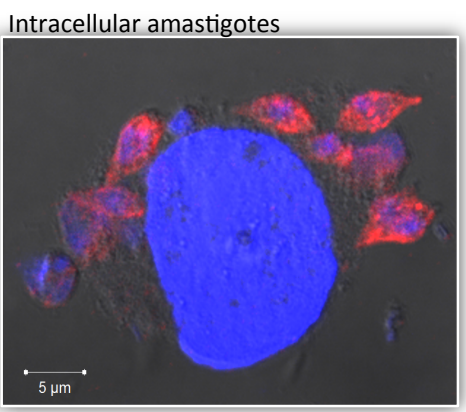

Fig. 3. LdAAP24 undergoes partial degradation during first $48 \mathrm{~h}$ of macrophage infection. 
Figure 4
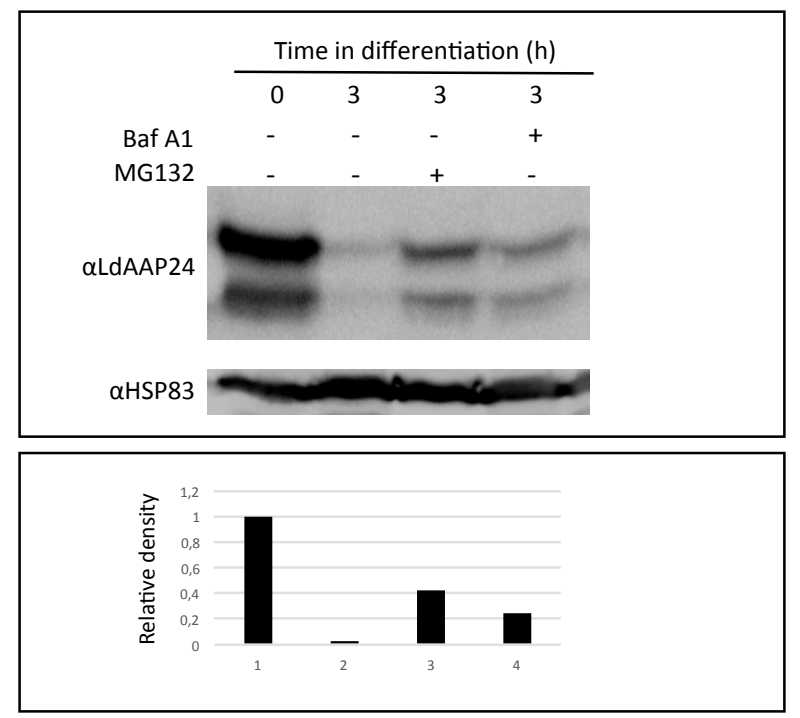

Fig. 4. LdAAP24 degradation is lysosome and proteasome-dependent. 
Figure 5

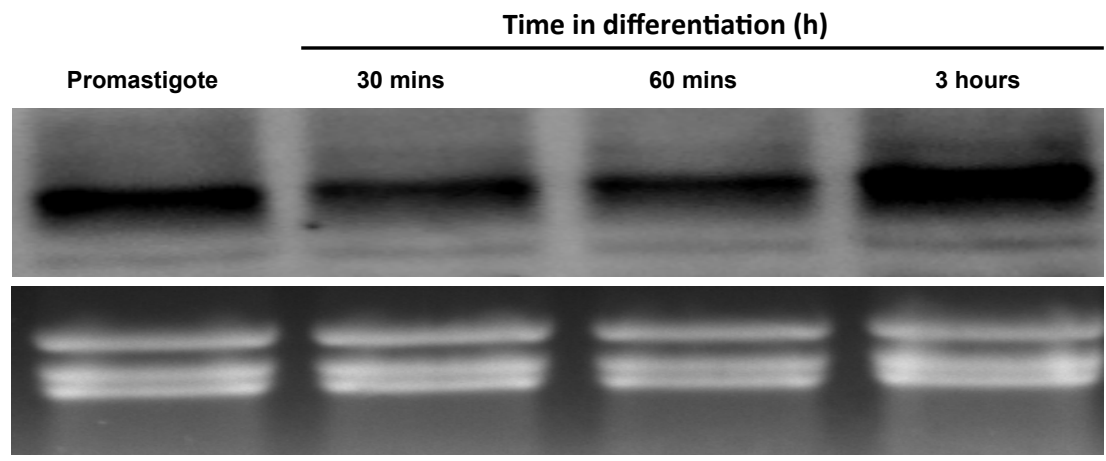

Fig. 5. mRNA levels of LdAAP24 do not change during axenic differentiation. 